\title{
A Longitudinal Study of the Use of Computer Supported Collaborative Learning in Promoting Lifelong Learning Skills
}

\author{
Ada W.W. MA \\ Department of Mathematics, Science, Social Sciences and \\ Technology, The Hong Kong Institute of Education, Hong Kong \\ SAR, China
}

ama@ied.edu.hk

Abstract

To survive and thrive in the challenging context of the 21st century, education must keep abreast of global trends, including the priority of developing in learners the capability of lifelong learning for enhanced cooperation, care, reflective abilities, critical capacities and creativity. As a potential approach to achieve this goal, Computer Supported Collaborative Learning (CSCL) is receiving increasing attention, as it revolutionizes the way of learning. The ultimate success of CSCL, however, often depends upon resolving the question of how it can be assessed in ways that are credible and reliable and how the technology-driven environment can enhance learning. Little guidance is found in the literature on the assessment of CSCL prompts the researcher to re-examine the role of assessment in learning and attempt to devise a peer assessment design in a technologyenhanced environment as part of the learning activities for full-time teacher-educators. In the three studies of this project, the creation of assessment rubrics, the submission of intra-group reflective journals, which formed the basis of the group's growth (learning process), and the intergroup review, which gained from peers' feedback to their project presentation and report (learning product) were incorporated as the assessment measures. It was encouraging to witness that learners of the same cohort had improved their lifelong learning skills progressively over the period of three years by engaging in peer assessment tasks. The findings of these studies indicated that skills fostered through peer assessment were highly relevant to the ir workplace as teachers when teamwork, interpersonal skills and the ability of self-reflection were emphasised. This study has demonstrated some good practice that supports student-centered learning, prepares students to be lifelong learners and which is suitable for adaption to suit other contexts.

Keywords: CSCL, peer assessment, technology-enhanced assessment, lifelong learning

Material published as part of this publication, either on-line or in print, is copy righted by the Informing Science Institute.

Permission to make digital or paper copy of part or all of these works for personal or classroom use is granted without fee provided that the copies are not made or distributed for profit or commercial advantage AND that copies 1) bear this notice in full and 2) give the full citation on the first page. It is permissible to abstract these works so long as credit is given. To copy in all other cases or to republish or to post on a server or to redistribute to lists requires specific permission and payment of a fee. Contact Publisher@InformingScience.org to request redistribution permission.

\section{Literature Review}

\section{Lifelong Learning and CSCL}

Life long learning refers to the idea of learning as a lifelong process with emphasis on the individual learner having the ability and responsibility to influence his or her own learning (Aspin \& 
Chapman, 2007). A universal and consensual understanding of lifelong learning is unattainable as definitions of the theory vary between nations, regions, and fields of study, making it a slippery concept (Tuijnman, 2002). However, it is best understood in this research project as a process of individual learning across a life span from cradle to grave. It embraces not only education in formal settings, but also "life-wide" learning in informal settings at home, at work or in the broader community.

Life long learning is seen as creating important economic and social effects. A combination of work productivity and education can focus on an entire life span instead of only the middle period. It is thought to represent a strategy for enhancing a nation's stock of human capital, which is seen as a necessary determinant for achieving rapid technological expansion and, by extension, macro-economic growth (Rubenson, 2001). Tuijnman (2002) indicates that a framework for lifelong learning should foster the personal development of the individual, counter risks to social cohesion, develop civil society through promoting democratic traditions, and enhance labour market flexibility. In this sense, life long learning can have a strong instrumental value and Hong Kong education shares this vision of life long learning.

In order to develop a school curriculum for the 21st century, and to meet the needs of students and society, it is a policy priority to provide lifelong learning experiences through the school curriculum with emphasis on development of generic elements for lifelong learning throughout all stages of schooling and across the key learning areas. Computer supported collaborative learning (CSCL) is regarded as one of the most promis ing innovations to learning and teaching creating new opportunities for conceptualizing, designing and facilitating collaborating learning. CSCL is receiving increasing attention in different educational scenarios (cf. Dewiyanti et al., 2007; Ewing \& Miller, 2002; Gillies, 2004; Nachmias, Mioduser, Oren, \& Ram., 2000; Resta \& Laferriere, 2007; Shellens \& Valcke, 2005; Wegerif, 2004). With the advent of computer technology, and more recently the wide accessibility of communication technology, the collaborative learning concept is undergoing reformulation because the way that learners assimilate information is changing radically, requiring concomitant pedagogical reform. By working together in the new computer-supported environment, it is believed that; (a) the setting of activity, (b) the dynamics of the interactions, (c) the support of members' equal opportunity to participate and contribute, (d) the configuration of the group; and (e) the variety of communication used for interacting will provide ample space for learners to achieve shared understanding and co-create knowledge (Nachmias et al., 2000, p. 95). It is anticipated that these features will significantly support the development of life long learning capabilities, namely research abilities, information technology, critical reflection, collaboration, creativity and higher order thinking, to cope with the exponential growth of know ledge in contemporary society as well as develop generic skills valued in the workplace.

The ultimate success of CSCL, however, often depends upon resolving the question of how it can be assessed in ways that are credible and reliable and how the technology-driven environment can enhance learning. Little guidance is found in the literature on the assessment of CSCL prompts the researcher to re-examine the role of assessment in learning and attempt to devise a peer assessment design in a technology-enhanced environment as part of the learning activities for this project.

\section{Role of Assessment}

It is generally accepted that modelling and promoting good assessment practices will enhance the quality and culture of assessment, which has been identified as a major barrier to improving education in Hong Kong (Keppell, Au, \& Ma, 2005). Student learning is very much driven by the assessments that they undertake and good assessment practices contribute to the creation of desired learning outcomes. Good assessment practices also provide an incentive to life long learning 
as experiences gained in self-monitoring and self-management of predictive, summative and concurrent performance lead to improved performance for future work and continuous professional development.

Assessment is an integral part of the learning experience for students. It should be about finding out about the quality of students' learning and of teaching more effectively, as it allows an examination of what the student knows and does not know (Keppell, Au, Ma, \& Chan, 2006). Ideally assessments "encourage interest, commitment and intellectual challenge" (Ramsden, 2003, p. 180). Formative assessment is fundamentally about good teaching and learning by allowing students to improve their performance on the same task, including both feedback and selfmonitoring. The fundamental goal of assessment is to improve student learning. Assessment has a key role in teaching and learning because students define the curriculum or module according to the assessment. The assessment also sends explicit and implic it messages to students about what is considered important in their learning. Assessment should be for learning, not of learning. As assessment has such an influence on learning, inappropriately designed assessment can negate its usefulness as a teaching and learning strategy (Boud, Cohen, \& Sampson, 1999).

\section{Assessment to Promote Collaborative Learning - Its Merits and Difficulties}

Assessment of collaborative learning is problematic as assessment is conventionally framed to deemphasise collaboration fostered in collaborative learning. Boud et al. (1999) identified difficulties in assessing peer learning as follows; (a) competitive assessment was emphasised in most educational institutions and collaboration was regarded as cheating in an individualistic view of assessment (Kohn, 1993, in Boud et al., 1999, p. 418), (b) traditional assessment exercised power and control over students in which choice in assessment was often illusory and collaboration was discouraged through the influence of overriding assessment paradigms, (c) assessment exerted a backwash effect on learning and inappropriate forms of assessment made students conform to the narrowest interpretations of assessment tasks, and (d) overload of tasks discouraged deep approaches to learning which implied that overloading was likely to lead peer learning activities to be either ignored or fall into disrepute.

To validly assess the collaborative outcomes of peer learning requires an approach differing from the traditional methods that rely on assessment as a means of ranking students. Assessment should not be seen as a phase at the end of a course but as a tool to provide feedback to students for learning gains rather than to evaluate them for course grades (Macdonald, 2003). It should be taken as something that is much broader than formal final testing in which it makes students more responsible and facilitates them, on a voluntary base, to make better-founded decisions about their study choice (Swan, Shen, \& HIltz, 2006). If students are expected to collaborate and work together, the notion of assessing them in terms of a group focusing on specific processes such as leadership, negotiation and conflict management, participant interactions, task performance, reflection as well as provision of feedback rather than individual outcomes can appear attractive (Boud, 2001; Resta, Awalt, \& Menchaca, 2002).

To capitalise on the effectiveness of collaborative learning and to ensure development of students' sense of ownership and control over the ir work, it is considered educationally sound to engage students in peer assessment (Oldf ield \& MacAlpine, 1995; Orsmond, Merry, \& Reiling, 2000). Peer assessment, a student-centred and a formative method of evaluation, has been described as a natural process used from childhood onwards to make critical judgment of peers (Fry, 1990). There is strong evidence that peer assessment is an effective device for encouraging good group management practices and enforcing a degree of discipline for the students to engage in meaningful cooperative work (Gatfie ld, 1999). In the past two decades, various studies had been conducted to test the validity and reliability of peer assessment and the findings had been desir- 
able (Falchikov, 1995; Gatfield, 1999; Kwok \& Ma, 1999; Orsmond Merry, \& Reiling, 1997). Sivan (2000) further summarised the contribution of peer assessment to learning processes as (a) developing students' critical appraisal skills, (b) increasing the ir awareness of a range of solutions to problems, (c) developing the ir reflective skills, and (d) promoting the development of selfreliance and self-directed learning. Peer assessment is, in particular, relevant to today's workplace where teamwork is emphasised, and the ability to assess the performance of oneself and one's peers is essential (Brown \& Knight, 1994). These capabilities should better prepare our learners to adapt to new environments after schooling.

\section{Technologyenhanced Assessment - Is This an Answer or a Question?}

To value and encourage student ownership of learning and to promote collaborative learning, peer assessment is introduced as an instrument to coach students to observe and manage their own learning progress, which will provide opportunity for more meaningful and interactive feedback to guide students towards learning. However, assessments with delayed feedback do not seem to change the learning process dramatically. Brown and Knight (1994), presenting a theory of formative assessment, suggested that to be effective feedback must be rapid and provided at an appropriate point in the learning process. Effective feedback should be diagnostic and prescriptive, so that recipients of such feedback could actually use it to guide their future learning.

The question posed here is how feedback can be delivered in a flexible and cost-effective manner. The judicious use of technology in which it plays a subsidiary role to stimulate new ways of working, new media avenues for expression, and to foster communication at a distance, may ease the task. Within Hong Kong, technology is often considered to be hardware and software (Keppell, Au, Ma, \& Chan, 2005). Furthermore, Jonassen, Howland, Moore, and Marra, (2003) have suggested that educators have traditionally attempted to encourage learning from technology. To promote learning, a broader notion of technology needs to be considered. Technology is a process of enhancing teaching and learning; a process of empowering our learners; a process of equipping our students with necessary skills needed for the future; and a process of using tools to enrich learning. Technology is seen as an enabler and provides enhancement and enrichment for the learning task.

Wang and Kinuthia (2004) further define technology-enhanced learning environments as having four characteristics: "using technology to motivate people, using technology to enrich learning resources, using technology to implement learning and instructional strategies and using technology to assess and evaluate learning goals" (p. 2725). In fact "networking opens up possibilities for enhancing formative feedback to students through peer review, when scripts are posted electronically for comment and review" (Macdonald, Weller, \& Mason, 2002, p. 10). The effectiveness of conducting peer assessment over the technology-enhanced environment has been further evaluated and confirmed by various studies. Thelwall's (2000) study found that computer-based assessment was an extremely versatile educational tool and could have a number of major advantages, including: increased lifespan, security and flexibility, improved student motivation for study, and use as a learning resource. Chang (2001) further reflected that most students had a positive attitude towards the system's assistance in personal learning process and outcome. Using the Web and associated technologies in assessment delivery has been gaining in popularity since the possible benefits to learning have been recognised. Davies (2000) summarised the merits of online peer assessment which enabled learners to; (a) see how others work and identify good practice, (b) use other's work as a benchmark to judge their own understanding and ability, and (c) look at the work that they themselves produce from a marker's point of view and be more selfcritical. The speed of the return of the marks and written comments were highlighted as the main benefit of the system. 
Alongside its advantages, technology-enhanced peer assessment obviously has some disadvantages. Notably, most of the computerised-based assessments cannot build higher thinking skills if they are linear. For example, multiple choice questions fail to assess competencies such as cooperation and critical reflective skills promoted by collaborative learning (Buchanan, 2000). These are qualitative aspects that require human judgement.

To further explore the feasibility and efficiency of technology-enhanced peer assessment, a more systematic research has to be conducted. The next section describes a technology-enhanced peer assessment design and implementation strategy using the Blackboard Learning System ML(C) to promote lifelong learning skills, in particular, collaboration, lateral thinking skills, reflective practices among learners and between learners and educators, as well as creative capabilities beyond the normal face-to-face classroom settings with a shift away from the traditional methods of assessment.

\section{Methodology}

\section{A Technology-enhanced Assessment Design Framework}

To explore if peer assessment could promote CSCL in fostering learners' with life long learning capabilities, efforts were made to design an approach that was educationally sound with the potential to assess the lateral skills of learners. This research project intended to give an indication if a technology-enhanced authentic peer assessment could foster collaborative learning by studying how learners interact in intra-groups and in inter-groups. The design of the study was shown in Figure 1. This project comprised three individual but connected studies and the performance of the same cohort of students was observed over a period of three years. Students were required to conduct an intra-group reflection which forms the basis of the growth of the group by critically evaluating the ir progress (learning process) as well as giving suggestions on strategies to enhance the group's effectiveness through submiss ion of an electronic bi-weekly reflective journal. Partic ipants were also required to perform an inter-group assessment by giving feedback and grades to their peer's project presentations and reports(the learning product) via the Blackboard Learning System ML(C) to promote their life long learning skills. The focus of the assessment, however, was on development, not evaluation and on cooperation, not competition.

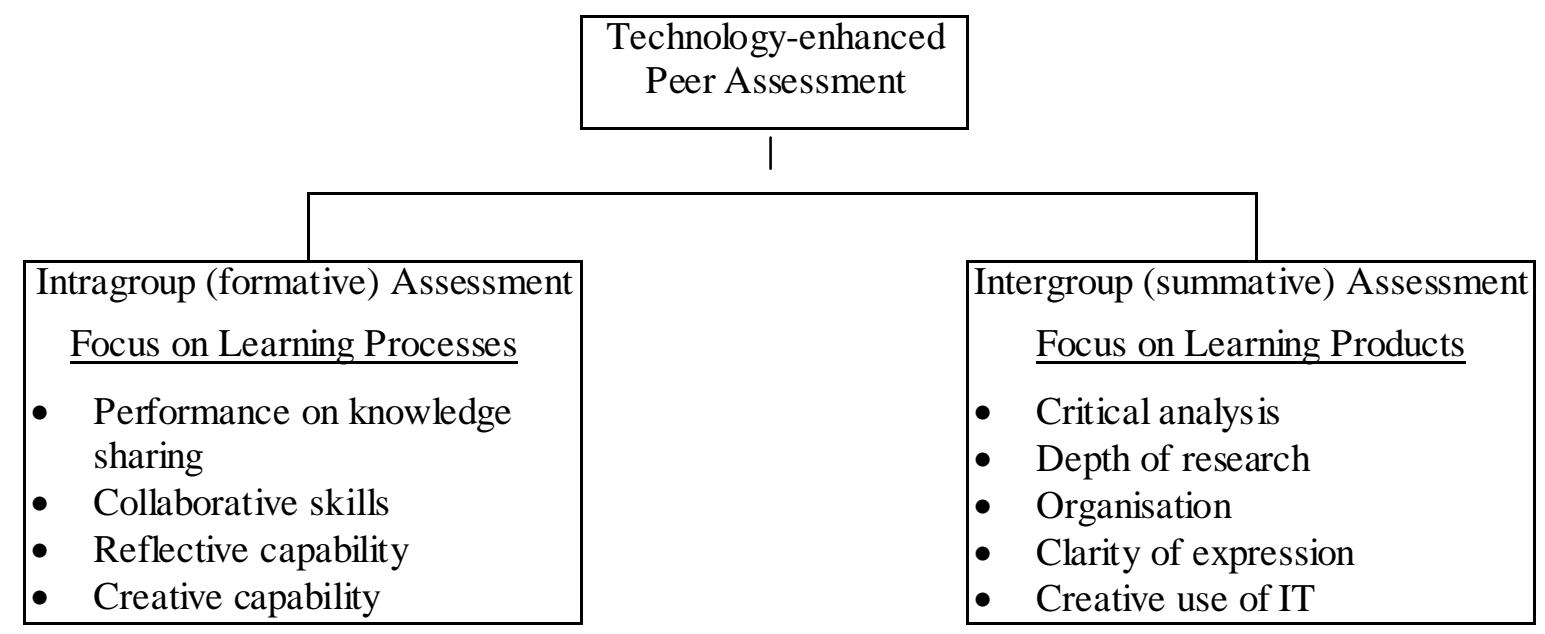

Figure1. A Web-based peer assessment design frame work 
To create online peer assessment activities that both reflect basic principles of social cognition and follow an authentic assessment design process, the following technology-enhanced peer assessment design was used.

\section{Learners' role}

Participants were first year students enrolled in the Bachelor of Education (Secondary) program in the field of Home Economics at the Hong Kong Institute of Education. The study was restricted to the module of Textile Studies and the module of Fashion Applications and Consumerism. Eighteen full-time students and 26 part-time in-service students participated in a total of three studies that together form the project. The devised collaborative assessment activities were summarized as follows:

First year - Study 1 involved six groups of 4-5 students involved in a 7 week project. The topic was an investigation on the evolution of fashion through culture, technology, society and civilisation and explicitly aimed to promote learners' higher-order thinking skills. Students participated in intra-group online discussions; submitted bi-weekly electronic reflective journals; and conducted intergroup online peer assessment.

Second year - Study 2 involved five groups of 4-6 students involved in a 5 week project. The topic was developed around an investigation, incorporating the social inquiry approach, of a consumer issue relating to the apparel industry. It was designed to foster learners' critical reflective capabilities. Students were required to conduct intra-group arguments online in the first 3 weeks of the project period and submit a final PowerPoint presentation for intergroup online debate in weeks 4 and 5. Participants were also required to submit intra-group weekly electronic reflective journals.

Third year - Study 3 involved four groups each with three participants, involved in a 6 week project. The task was the development of a portfolio of fashion illustrations for specific interpretation or performance, utilising Photoshop as the electronic medium. The task was designed to cultivate learners' creativity. Students participated in intra-group developmental design where they provided feedback and design sharing to group members. Participants were required to submit intra-group weekly electronic reflective journals.

\section{Assessment tasks}

Ideally, the assessment approach formulated for this project promoted transferable skills that students could apply to other courses and real-world professional settings. In this way it was expected to promote lifelong learning and was linked to generic capabilities of teamwork and interpersonal skills that were viewed highly by employers. The assessment tasks focused on real-life issues which were authentic. For example, in the third case study, students assumed the role of fashion designers in which they designed a project (fashion design with fabric and colour illustrations) that was subject to ongoing peer critique. The tasks are ill-structured and complex challenges integrated the assessment with learning outcomes, activities, and the class. For instance, in the second task, the project was very challenging as it required the students to examine the underlying message in fashion advertisements and question the taken-for-granted assumptions that had been perpetuated. Therefore, the formative assessment tasks become a continuous and diagnostic activity throughout the learning processes which allows students to make numerous changes based on feedback from students and teachers in both the face-to-face setting and the online learning environment. 


\section{Peer assessment tool}

A networked online platform, the Blackboard Learning System MLC), was utilised to facilitate prompt feedback and sharing of information. Learners and researchers discussed learners' work as it progressed by means of asynchronous tools including discussion forums, e-mails and newsgroups as well as synchronous tools such as chat room. Projects were posted for sharing and critique among groups.

\section{Educator's role}

Although the assessment tasks were learner-centred, this did not mean that students could be given complex and authentic tasks with no support or coaching to guide their learning. The role of the educator in fostering these interactions was critical.

\section{The Implementation Plan}

Assessment items devised in this project were group projects compris ing $100 \%$ of the assessment marks. It is not possible for the facilitator to observe the entire process whereas a learner's peers often have the opportunity to observe other group members' performance. However, the lack of experience in assessing the ir peers affects the learners' confidence in peer assessment (Sivan, 2000). Thus, the researchers conducted a briefing session at the beginning of the semester, allowing ample time to assimilate the concept of the project and to expla in learners' contribution to peer assessment. The ideas of using an online assessment system were further articulated with a demonstration session by a research assistant, providing learners with substantial hands-on time for practicing the electronic procedures. Each collaborative assessment task was carried out in the following four stages.

\section{Stage one - Set assessment criteria}

It was reported that the reliability of peer assessment would be improved if learners were given detailed guide lines as how to grade work (Oldfie ld \& MacAlpine, 1995) and the assessment criteria were well explained (Falchikov, 1995). Additionally, learners would take a more active role in learning and develop a sense of ownership which related to both the meaning of the criteria and the worth of the criteria in terms of marks to be awarded if they were involved in identifying and creating assessment criteria (Boud et al., 1999; Brindley \& Scoffield, 1998; Fry, 1990; Orsmond et al., 2000). In this study, assessment criteria initially proposed by the researcher were negotiable. During the discussion, the meaning of each criterion was clarified and the peer groups arrived at an agreed set of criteria. The criteria were then displayed on the module web page for easy reference and use during the module delivery.

\section{Stage two - Implement the intra-group assessment}

All materials submitted were presented in electronic format. Learners were given the opportunity to include personal reflections biweekly about the progress. Researchers could give learners feedback on their learning processes and outcomes throughout the semester, whereas learners could also self-assess on the performance of group members at any place and any time. The biweekly reflective journal was also a formative assessment to encourage reciprocal communication and openness to feedback among learners.

\section{Stage three - Implement the inter-group assessment}

At the end of a collaborative task, each group was required to submit multimedia projects in digital format and softcopy of the reports to be uploaded to the server to facilitate inter-group peer assessment within two weeks after the submission.. Each group marked the other groups' per- 
formance and no individual marks were to be awarded. Learners could receive prompt feedback from the lecturers as well as other learners easily.

\section{Stage four - Collect data for evaluation}

The data were collected using two means. Quantitative information was collected when participants completed the online inter-group peer assessment table. These data were then analysed to examine if the peer assessment grades were reliable. Qualitative information was gathered by analysing the ir online reflective journals. The qualitative data were then analysed to explore if writing reflective journals made group dynamics transparent. Focus group meetings were conducted with the aim of obtaining an in-depth understanding of participants' views on the effectiveness of peer assessment to foster collaborative learning and fostering of lifelong learning capabilities. Participants were encouraged to give suggestions on improving this assessment pedagogy and all meetings were tape-recorded.

\section{Findings}

Did the online peer assessment promote collaborative learning and improve group dynamics?

\section{Are the peer assessment grades reliable?}

For the first assessment task, students attempted to grade inter-group member's final submission of their project, a task focusing on an investigation into the evolution of fashion through culture, technology, society and civilisation. Each group provided marks to peer performance by (1) putting a tick against the itemized rubrics with rating scores 5 to 1 ; (2) giving overall score to peer performance. Scores given by each group were added up as total scores. The mean of the total scores would check with the HKIEd marking scheme to identify the grade of group performance. An analysis was conducted to examine if the peer assessment grades were reliable as follows in Table 1

Table 1. Group scores for project

\begin{tabular}{|c|c|c|c|c|c|c|c|c|c|c|}
\hline \multirow{3}{*}{$\begin{array}{l}\text { Groups } \\
\text { Being } \\
\text { Assessed }\end{array}$} & \multicolumn{8}{|c|}{ Assessor } & \multicolumn{2}{|c|}{ Ranking } \\
\hline & \multirow{2}{*}{\multicolumn{4}{|c|}{ Group }} & \multirow{3}{*}{$\begin{array}{c}\text { SD } \\
\text { Between } \\
\text { groups }\end{array}$} & \multirow{3}{*}{ Mean } & \multirow{3}{*}{ Lecturer } & \multirow{3}{*}{$\begin{array}{c}\text { SD. } \\
\text { Students vs } \\
\text { lecturer }\end{array}$} & \multirow{3}{*}{$\begin{array}{c}\text { By } \\
\text { Lecturer }\end{array}$} & \multirow{3}{*}{$\begin{array}{c}\text { By } \\
\text { Student }\end{array}$} \\
\hline & & & & & & & & & & \\
\hline & A & B & $\mathrm{C}$ & $\mathrm{D}$ & & & & & & \\
\hline Group A & & 85 & 75 & 72 & 6.81 & 77.3 & 76 & 0.94 & 2 & 1 \\
\hline Group B & 75 & & 80 & 76 & 2.65 & 77 & 67 & 7.07 & 3 & 2 \\
\hline Group C & 70 & 80 & & 72 & 5.29 & 74 & 60 & 9.90 & 4 & 4 \\
\hline Group D & 80 & 70 & 80 & & 5.77 & 76.67 & 78 & 0.94 & 1 & 3 \\
\hline
\end{tabular}

The findings indicated that the mean of total scores for different groups given by both peer groups and lecturer was grade B according to HKIEd's marking scheme, (HKIEd Marking Scheme: A = $80-100 \%$; $\mathrm{B}=60-79 \%$; $\mathrm{C}=40-59 \%$ ). A closer analysis of the data, however, revealed a disagreement between students and facilitator on 'good' performance (Grade B) as the standard de- 
viation for the scores given by students and facilitator was high, especially to the performances of Group B $(\mathrm{SD}=7.07)$ and Group C $(\mathrm{SD}=9.90)$. The results implied that students were too lenient in marking their peers' work. The only agreement between students' and facilitator's marking was that they had both given Group $\mathrm{C}$ the lowest score. The grade differences between the mean of total scores given by students ( score $=74$ ) and facilitator $($ score $=60$ ) was large, which in turn showed how lenient students were in allocating marks to their peer's performances. Furthermore, different groups had very different ideas about their peers' performances. The standard deviation for the scores given by different groups was high (SD up to 6.81). Further investigation by focus group meetings was needed in order to explain such a difference. Individual assessment items were further analysed to explore if peer assessment grades were reliable (see Table 2).

Table 2. Individual assessment items to explore the reliability of the peer assessment grades for Group 14

\begin{tabular}{|c|c|c|c|c|c|c|}
\hline \multicolumn{4}{|c|}{ Assessed Group A } & \multirow[b]{2}{*}{ Facilitator } & \multirow{2}{*}{$\begin{array}{c}\text { SD } \\
\text { Between } \\
\text { groups }\end{array}$} & \multirow{2}{*}{$\begin{array}{c}\text { SD } \\
\text { Students vs } \\
\text { Facilitator }\end{array}$} \\
\hline Assessor (Group) & B & $\mathbf{C}$ & D & & & \\
\hline $\begin{array}{l}\text { Ability to } \\
\text { understand the } \\
\text { requirement of } \\
\text { the task }\end{array}$ & 5 & 3 & 4 & 4 & 1.00 & 0.82 \\
\hline $\begin{array}{l}\text { Accuracy of } \\
\text { analysis / } \\
\text { Appropriateness } \\
\text { of concl usions } \\
\text { drawn }\end{array}$ & 4 & 3 & 4 & 4 & 0.58 & 0.50 \\
\hline Depth of research & 4 & 3 & 4 & 4 & 0.58 & 0.50 \\
\hline $\begin{array}{l}\text { Organisation of } \\
\text { presentation }\end{array}$ & 5 & 5 & 3 & 5 & 1.15 & 1.00 \\
\hline $\begin{array}{l}\text { Clarity of } \\
\text { expression / } \\
\text { Appropriate use } \\
\text { of IT to suppor t } \\
\text { presentation }\end{array}$ & 5 & 4 & 3 & 4 & 1.00 & 0.82 \\
\hline Overall marks & 85 & 75 & 72 & 76 & 6.81 & 5.60 \\
\hline \multicolumn{4}{|c|}{ Assessed Group B } & & SD & SD \\
\hline Assessor (Group) & $\mathbf{A}$ & $\mathbf{C}$ & D & Facilitator & $\begin{array}{c}\text { Between } \\
\text { groups }\end{array}$ & $\begin{array}{l}\text { Students vs } \\
\text { Facilitator }\end{array}$ \\
\hline $\begin{array}{l}\text { Ability to } \\
\text { understand the } \\
\text { requirement of } \\
\text { the task }\end{array}$ & 3 & 4 & 4 & 4 & 0.58 & 0.50 \\
\hline $\begin{array}{l}\text { Accuracy of } \\
\text { analysis / } \\
\text { Appropriateness } \\
\text { of concl usions } \\
\text { drawn }\end{array}$ & 4 & 4 & 4 & 4 & 0.00 & 0.00 \\
\hline Depth of research & 3 & 4 & 4 & 4 & 0.58 & 0.50 \\
\hline $\begin{array}{l}\text { Organisation of } \\
\text { presentation }\end{array}$ & 4 & 3 & 3 & 3 & 0.58 & 0.50 \\
\hline
\end{tabular}




\begin{tabular}{|c|c|c|c|c|c|c|}
\hline $\begin{array}{l}\text { Clarity of } \\
\text { expression / } \\
\text { Appropriate use } \\
\text { of IT to support } \\
\text { presentation }\end{array}$ & 4 & 4 & 4 & 4 & 0.00 & 0.00 \\
\hline Overall marks & 75 & 80 & 76 & 67 & 2.65 & 5.45 \\
\hline \multicolumn{4}{|c|}{ Assessed Group C } & & SD & SD \\
\hline Assess or (Group) & $\mathbf{A}$ & B & D & Facilitator & $\begin{array}{c}\text { Between } \\
\text { groups }\end{array}$ & $\begin{array}{l}\text { Students vs } \\
\text { Facilitator }\end{array}$ \\
\hline $\begin{array}{l}\text { Ability to } \\
\text { understand the } \\
\text { requirement of } \\
\text { the task }\end{array}$ & 3 & 4 & 3 & 4 & 0.58 & 0.58 \\
\hline $\begin{array}{l}\text { Accuracy of } \\
\text { analysis / } \\
\text { Appropriateness } \\
\text { of conclusions } \\
\text { drawn }\end{array}$ & 2 & 4 & 3 & 4 & 1.00 & 0.96 \\
\hline Depth of research & 2 & 5 & 4 & 4 & 1.53 & 1.26 \\
\hline $\begin{array}{l}\text { Organisation of } \\
\text { presentation }\end{array}$ & 3 & 4 & 4 & 3 & 0.58 & 0.58 \\
\hline $\begin{array}{l}\text { Clarity of } \\
\text { expression / } \\
\text { Appropriate use } \\
\text { of IT to support } \\
\text { presentation }\end{array}$ & 4 & 3 & 4 & 3 & 0.58 & 0.58 \\
\hline Overall marks & 70 & 80 & 72 & 60 & 5.29 & 8.23 \\
\hline \multicolumn{4}{|c|}{ Assessed Group D } & & SD & SD \\
\hline Assess or (Group) & $\mathbf{A}$ & B & $\mathbf{C}$ & Facilitator & $\begin{array}{c}\begin{array}{c}\text { Between } \\
\text { groups }\end{array} \\
\end{array}$ & $\begin{array}{l}\text { Students vs } \\
\text { Facilitator } \\
\end{array}$ \\
\hline $\begin{array}{l}\text { Ability to } \\
\text { understand the } \\
\text { requirement of } \\
\text { the task }\end{array}$ & 4 & 4 & 4 & 5 & 0.00 & 0.50 \\
\hline $\begin{array}{l}\text { Accuracy of } \\
\text { analysis / } \\
\text { Appropriateness } \\
\text { of conclusions } \\
\text { drawn }\end{array}$ & 4 & 3 & 4 & 5 & 0.58 & 0.82 \\
\hline Depth of research & 3 & 3 & 4 & 4 & 0.58 & 0.58 \\
\hline $\begin{array}{l}\text { Organisation of } \\
\text { presentation }\end{array}$ & 4 & 4 & 4 & 5 & 0.00 & 0.50 \\
\hline $\begin{array}{l}\text { Clarity of } \\
\text { expression / } \\
\text { Appropriate use } \\
\text { of IT to support } \\
\text { presentation } \\
\end{array}$ & 4 & 4 & 4 & 4 & 0.00 & 0.00 \\
\hline Overall marks & 80 & 70 & 80 & 78 & 5.77 & 4.76 \\
\hline
\end{tabular}

Key:- 5 = Excellent; 4 = Good; 3 = Satisfactory; 2 = Fair; 1 = Fail 
With reference to Table 2, it was found that students' concepts on individual criteria items seemed to be generally consistent, both within the groups and when compared to the facilitator's and the standard deviation of the scores for individual items was low ( $\mathrm{SD} \leqq 1)$. It suggested that their understanding on marking criteria was clear. The criteria for overall scores, however, were not well understood by students as the overall scores they allocated were inconsistent with the itemised scores. The standard deviation of the overall scores was high; there were variations between overall scores given by groups and the facilitator and students were not clear about the score ranges for itemised grades $(1,2,3,4 \& 5)$.

There were two possible explanations the variations in the scores given by students to peers.

Based on the information obtained from the focus group meetings, students' understanding of the mark ranges was relatively weak. In addition, they did not feel comfortable in commenting on their peers' work and they admitted that their marking technique still had space for improvement.

\section{Did the peer assessment promote collaborative learning?}

Overall, students claimed that they had learnt how to be constructively critical, as evidenced in the comments that follow:

When there are a few assignments placed in front of you, you can compare them and tell which one is better. This also allows you to learn from others' assignments. In addition, we can learn how to be critical. (GB-S2)

Peer assessmentforces us to read others' assignments. Normally, we will not look at the assignment again once it is finished. We usually think that our own work is perfect, if not, you will not have handed it in. It is easier to pick on others' work, but when you write your comments, you will make some adjustment. (GA-S3)

In order to be a good assessor, you should be neutral and point out both the good and bad things in others' work. (GD-S2)

You can learn information of other topics by marking others' assignments and learn how to give constructive comments without hurting others. (GA-S1)

You will use the good things you see in others' assignments and reflect in your own work. (GC-S3)

The focus group meeting with the learners revealed that peer assessment for this task was of little value to collaborative learning and group dynamics. Learners indicated that their main difficulties in the marking process were fourfold: (1) inexperience with the peer assessment practice, (2) clarity of the mark ranges, (3) unwillingness to take peer assessment as formal assessment, and (4) heavy workload as seen in the following comments:

We lacked the confidence to criticize others' work as we were not competent in mark ing. We might not have the professional knowledge to justify the quality. (GD-S2)

We were not clear about the marking as we did not have such marking experience before. We would be more competent in doing it next time. (GC-S1)

We were not certain about the mark ranges that were relevant to various grades. That's why the final marks given seemed to be different to the lecturer's, though the grades given were similar. (GC-S2)

I lacked the confidence in grading as the mark range was too boardfor a particular grade. $(G B-S 1)$ 
Group project is good for practice and improvement, but it is not suitable to be used as part of formal assessment. (GA-S1)

The workload is huge and it's time consuming to conduct the inter-group peer assessment. But it provides us a golden opportunity to learn collaboratively. (GC-S3)

\section{Critical Reflection on the Peer Assessment Design to Promote Collaboration}

In summary, the overall outcome of this assessment task was disappointing. The evaluation was not well received by students as they gained little from this inter-group peer assessment. They claimed that they did not have any experience in conducting peer assessment and found the mark ranges for respective grades very confusing. These findings appear to be consistent with those obtained in previous research. Sivan (2000) confirmed that the lack of experience in assessing work would affect the learners' confidence in peer assessment. Despite the fact that a briefing session on peer assessment was conducted, a trial-run might have been useful to enhance learners' skills in this area. The learners were quite clear about the negotiated marking criteria but the clarity of mark ranges were overlooked which affected the reliability of the marks given. The results implied that a more thorough preparation for peer assessment would be essential for its success.

Perhaps the main issue arising from this unsuccessful practice was that the intergroup peer assessment was formal. It was found that this assessment practice had inevitably shifted the focus of the assessment from collaboration to competition. As soon as learners were asked to assess peer's contribution to a project or group activity (for formal grades), the nature of the collaborative learning relationship changed, thereby implicitly sending an inappropr iate message to learners about the focus and value of collaborative learning.

To be a reflective educator, the inter-group peer assessment tasks had to be redesigned to put the practice in the right place to promote learning. It was suggested that formal peer assessment which led to student grades should be avoided for the remaining two assessment tasks as it could disrupt collaboration among learners and lead to jealousies and resentment. Peer assessment could focus on ongoing peer feedback conducted in an informal way. Such a proposal, however, could be problematic as formal assessment is a direct indicator of the importance of the assessment tasks commonly perceived by learners. If collaborative learning and group work are valued in the learning process, peer assessment has to be weighted accordingly or the learners will not take it seriously. To counteract this problem, the provision of ongoing feedback to inter-group performance could be the pre-requisite for the completion of the assessment tasks. The importance of providing quality peer feedback that is specific, descriptive, predominantly nonjudgmental in tone and form, and directed towards the goals of the recipients, and the peer involvement in the exercise might be emphasised.

\section{Did the Created Peer Support System within the CSCL Environment Foster Critical Reflective Capabilities?}

\section{Briefing on the assessment design}

A group project was undertaken, in which students were required to undertake a critical analysis of a fashion magazine, investigating:

- Whose interests are being served here?

- Who is advantaged? Who is disadvantaged?

- What issues of justice and injustice does this raise? 
- What unquestioned assumptions about society are evident here?

Students were required to write an intra-group reflective paper discussing the findings of the investigation and drawing conclusions based on the study, with critical reflections on the following items:

- What is the intention behind including/excluding certain groups?

- What impact do these articles/colour plates/advertisement have on the reader?

- Who stands to benefit?

- At what cost and at whose expense do they benefit?

- What can be done to address this situation?

To make the intra-group dynamic transparent and to add further dimensions to the experience, submission of a reflective journal was a prerequisite for the completion of the task as journal writing in itself is seen as a valuable stimulus to encourage reflection on practice (Gillies, 2004;

Kember et al., 1999; Kreijins \& Kirschner, 2002; Wegerif, 2004). Journal writing is a precursor to critical reflection within groups. As the group remains large ly invisible to the educator, the educator needs to pay closer attention to the quality of argument in critical debates within the group. Hence, members of each group were required to conduct self-reflection first which would then be followed by intra-group analysis and critique.

Students were required to prepare a presentation summarising the findings for inter-group peer questioning and debate. Intra-groups would have a chance to raise new perspectives for the subsequent dialogue and write reflective reports before final submission.

\section{Feedback elicited from focus group meetings}

It was evident that students perceived conducting intra-group reflection with the submission of weekly reflective journals as a useful practice to promote their reflective capabilities, selfmonitoring skills and openness to feedback among the other learners.

When I knew I had to submit reflective journals, I thought it was just a formality and did not take the work seriously, feeling that it was useless to my study. But when I started to prepare it on a weekly basis and after four weeks I looked back my work, I realized I had improved a lot! (GA-S3)

Usually we made reflections on our learning after we had submitted our assignment. Weekly submission of reflective journals made us to conduct on-going reflections during the learning process which allowed us to come up with a course of actionfor improvement. $(G B-S 2)$

My capacity to make reflection was stronger. After I had read others' comments, I would re-think them again and make judgments. If I did not agree with them, I would search for more information to support my views. (GC-S3)

The shift of the peer assessment design to informal ongoing feedback about peer performance within the same cohort of learners resulted in significant improvement in their learning. Most students indicated that the ongoing peer critique conducted in the CSCL environment did foster their critical inquiry skills. The follow ing comments illustrate this:

Our critical analysis (intra-group discussion) on advertisements had been promoted. We no longer believed in what the advertisements had tried to portray now. We challenged whether the advertisements had carried any hidden messages that we had taken for granted in the past. (GC-S1) 
We might be subjective in many ways, yet this mode of interaction provided us a chance to reflect on how we made judgments to form our perspectives. It also fostered our openness to peers'feedbacks as well. (GA-S1)

(Inter-group peer critiques) helped us to identify our bias and deficiencies as peers commented at our work from different perspectives. (GA-S2)

After several rounds of discussion (inter-group peer critiques), our critical thinking skills had been promoted as the findings were come up with thorough thinking. (GB-S2)

One's thought was highly related to one's background and characteristics. Without the interaction from online discussion, we might perceive the world with bias. (GC-S2)

Further, performing instant peer critiques online, challenging assumptions with multiple perspectives through social interactions, ongoing support from the facilitator in the learning process as well as building trust and strengthening team spirit among the groups were highlighted as enhancing the learners' critical reflection:

Our discussion and reflective skills had been improved as I could obtain more instant feedbacks form classmates online. (GC-S1)

I had chances to make a lot of good friends who gave me a lot of valuable suggestions in online discussion which had broadened my perception of the world. Our mutual trust had been built and became more open to others' comments. (GE-S1)

Without this experience of online critical inquiry, one might believe that learners were not able to manage such mode of learning. I had tried it out in my secondary teaching; it worked well with students as they remarked that they could think more deeply with peers' critiques. (GA-S2)

Our lecturer had been following us very closely and her supportive feedbacks highly motivated us to pay more effort on discussion the next time. Her encouraging comments also helped us to build up our confidence on the tasks. (GB-S3)

Student comments indicated that they were largely positive about the assessment process and this positive attitude implied that benefits would have been gained. Their opinions on both the work of their peers and the process of assessment were valued.

\section{Did the Ongoing Peer Critiques within the CSCL Environment Cultivate Creativity?}

\section{Briefing on the assessment design}

In this study, students were assigned to a design project (fashion design with fabric and colour illustrations), which involved the use of peer sharing and critique using the Blackboard Learning System ML@.. Each group developed the assessment rubrics for their own design works. The criteria were then displayed onto the module web page for easy reference during the course of module de livery. To ensure individual accountability, facilitate group processing and make group dynamics transparent, learners were required to conduct an intra-group reflection on the ir design processes, analyse their progress and give suggestions on methods and strategies to enhance the group's effectiveness through submission of an electronic weekly reflective journal. Developmental sketches of design work were posted on the Web for ongoing feedback and critique from peers and educators. It is believed that the learners' social skills, creativity, collaboration and critical reflective ability would be developed throughout this process. 


\section{Feedback elicited from focus group meetings}

It was evident that students perceived creating their own assessment rubrics, writing intra-group reflective journals, providing ongoing peer critique, and inter-group peer review as an appropriate assessment design. It motivated them to take a more active role in learning, to develop a sense of ownership, to encourage communication and openness to feedback among learners and to give quality feedback to others which would be of great value to their teaching careers and professional development as teachers. In summary, they valued this learning experience, as the following comments indicate:

The assessment rubrics were come up with our group discussion. We had learnt a lot from this process as it provided guidelines and directions for our assignment to work on. It also created incentive for own learning. (GA-S3)

The assessment rubrics guided us to think more deeply when giving feedbacks to the peers. (GA-S1)

I think the intra-group reflective journal can help us identify our strengths and weaknesses for improved course of action. It also acts as a tool for self-reflection and striving self-enhancement. (GD-S2)

We can look at other group's work with the inter-group peer assessment that provides chances for us to experience how a teacher gives marks and constructive comments. (GAS1)

I think the assessment design is a fairer and more balanced one, which is different from the past with the teacher as the sole assessor. Now, we can obtain reference both from peers and teachers. (GC-S3)

It is not sufficient to have just one summative assessment, as we will not have chances to improve our work. Formative assessments such as writing reflective journals and providing ongoing peer critique can guide us to learn step by step and to learn from trial and error. $(G A-S 2)$

Most students who used the online assessment package indicated that the speed of the return of written comments plus the increased opportunity for self-reflection and review were identified as the greatest benefits of the technology-enhanced assessment system:

I think the file exchang e feature of the platform facilitates the assessment process most as it provides a large volume of storage for us to share our work. (GA-S1)

We can capture our learning process by reviewing and revisiting our work as well as comments from peers and teachers from time to time. (GA-S2)

I think this is an advantage using e-learning platform as it promotes inter-group discussion and invites the teacher to be the co-learner as well. It also serves as a tool to make the group dynamic transparent. (GD-S3)

We can obtain instant feedbacks from peers and teachers for improvement. I realize that my work has been improved a lot because of other's inputs and feedbacks. (GC-S1)

The use of platform has changed the role of students in learning. Students now have the rights and access to provide feedbacks to peers. The teacher will no longer dominate such role. (GC-S2)

Although most of the learners were positive about the use of technology, one group raised a question that deserved the researcher's attention. There was an incident that members of an intragroup did not use the e-learning platform as the communication channel. They preferred to ex- 
change ideas face-to-face as "...we are full time students and we can get in touch with other members very easily...the interaction on e-learning platform is not as direct as the face-to-face one in which we can see others' facial expression. Sometimes, we shall also communicate via telephone" (GB-SYC). Other than Blackboard Learning System ML@, few students also claimed that they would use ICQ for communication as "... it is speedy and convenient. We can activate the program all the time, not only when working on assignments, which facilitates ideas exchange at all times" (GB-PYC).

It was believed that creativity and collaborative skills could be fostered by social support in terms of cognitive diversity and distribution of expertise (Arias et al., 2000; Fischer, 1999; Kvan et al., 1999). Most students remarked that the assessment tasks did foster their creativity and cultivate their positive attitudes toward collaboration and sharing within the created intrinsic reward environment which was highly regarded for their future careers and could be confidently promoted to the school environment when they became practicing educators:

I have tried out the peer's suggestions and modified my design and it really works! (GDS3)

Peer's critique helps us to sharpen our design ideas and to make the sketches more explicit and communicative to the audience. Their positive feedbacks can also train us to be more reflective and serve as a vehicle that can highly motivate us to work out a better piece of work. (GD-S2)

Design is very subjective. But peer critique provides us an opportunity to learn how to handle others' feedback and be open. (GA-S1)

We have received more than 10 feedbacks from our peers. Say for example, if we take 5 out of the feedbacks and make modifications, at least 5 different aspects of our design will have been improved. (GD-S3)

Peer's critique makes us to review our design work. As a result, our final version looks very different from our first draft. The improvement is really remarkable! (GA-S3)

Despite the fact that most of the learners were positive about the assessment activities, one group suggested that the period for the assessment tasks could be extended to allow learners to provide more feedback at various design stages for improvement. Boud (1995) confirmed that one of the practical constraints on using peer feedback was the amount of time required for students to comment.

\section{Discussion}

In any course, assessment must be congruent with the kinds of learning emphas ised in class. When collaborative learning and lifelong learning capabilities are promoted, all learning activities and assessment measures should reflect this emphasis. It was apparent that the critical peer assessments led to a greater self-awareness of their own abilities and performances that were especially important to student teachers. With reference to the feedback from participants of the focus group meetings, their perceptions on the effectiveness of computer supported peer assessment to foster collaboration and mastery of transferable life long learning capabilities was highlighted as follows:

The use of platform has changed the role of students in learning. Students now have the rights and access to provide feedbacks to peers. The teacher will no longer dominate such role. (GC-S2) 
I think the intra-group reflective journal can help us identify our strengths and weaknesses for improved course of action. It also acts as a toolfor self-reflection and striving self-enhancement. (GD-S2)

Formative assessments such as writing reflective journals and providing ongoing peer critique can guide us to learn step by step and to learn from trial and error. (GA-S1)

I think the assessment design is a fairer and more balanced one, which is different from the past with the teacher as the sole assessor. Now, we can obtain reference both from peers and teachers. (GC-S3)

After several rounds of discussion (inter-group peer critiques), our critical thinking skills had been promoted as the findings were come up with thorough thinking. (GB-S2)

The learners further emphasised that skills fostered through peer assessment were highly relevant to their workplace as teachers when teamwork, interpersonal skills and the ability of selfreflection were greatly promoted which were highly valued by school administrators. Learners committed that they would confidently promote these authentic assessment experiences to the school environment when they became the practicing educators:

We can look at other group's work with the inter-group peer assessment that provides chances for us to experience how a teacher gives marks and constructive comments. (GAS1)

Without this experience of online critical inquiry, one might believe that learners were not able to manage such mode of learning. I had tried it out in my secondary teaching; it worked well with students as they remarked that they could think more deeply with peers' critiques. (GA-S2)

The perceived benefits to learning from the technology-enhanced peer assessment exercises suggested the instrument and methodology provided a sound bas is for continued application to other subjects and disciplines.

In summary, it was encouraging to witness that learners of the same cohort (same group of students over three years) had grown progressively over the period of 3 years by engaging in peer assessment tasks. With reference to the feedback elicited from participants' focus group meetings, an in-depth understanding of the ir views over the effectiveness of computer supported peer assessment can be summarized as follows.

The assessment modes and strategies adopted served the fundamental goal of supporting deep learning (Ramsden, 2003). Peer assessment reflected the nature of social-cultural perspective of learning which facilitated sharing and distributing of knowledge and expertise among community members, stretching one's zone of proximity with inputs from peers of multitalents and knowledgeable facilitator (Ge, Yamashiro \& Lee, 2000). Authentic formative peer assessment of creating own assessment rubrics, writing intra-group reflective journals, and ongoing inter-group peer review was remarked as an appropriate choice to foster life long learning capabilities such as higher order thinking skills, critical reflective capabilities and creativity (Orsmond, et al., 2000; Shellens \& Valcke, 2005; Sivan, 2000; Wegerif, 2004).

\section{Conclusion}

Most of the participants were very positive with the technology-enhanced peer assessment experiences, however, there were challenges. Lessons learnt from the unsuccessful formal inter-peer assessment tried initially reinforced the importance of using peer assessment appropriately, as mismatch can inhibit learning and send inappropriate signals to students about the nature of collaborative learning within groups. Boud et al. (1999) suggested that asking students to formally 
assess each group within the context of a group project could lead to a lack of cooperation, because either implic itly or explic itly one group is competing against another. What we need to do is emphasise the group output or collective output and encourage students to provide peer feedback in developing this output. Peer assessment is about students providing feedback to each other for the benefit of the collective effort (Keppell et al, 2006).

Despite the fact that peer assessment provided considerable merit, online peer assessment with multiple groups could be very time-consuming for educators. Two steps might lessen the time required:

- Educators might limit the ir comments to final drafts, with students providing peer feedback on preliminary work. Alternatively, educators could have their own comments limited to one brief comment on an intermediate piece of work for each student or group, so that any important redirection is enabled before it becomes a problem for the student. Follow ing initial mode lling and support, students can be encouraged to manage their ongoing feedback process.

- Part of the overall assessment could be linked to the quality of students' feedback to peers and their participation in the online critique. This would encourage all students to be active in the assessment process.

The constant feedback gathered from students' evaluations of their learning did prove that there was gradual development of social skills, creativity, and critical thinking ability among the learners. It was apparent that the critical peer assessments led to a greater self-awareness of their own abilities and performances that were especially important to student teachers.

The findings of these three studies indicated that skills fostered through peer assessment were highly relevant to their workplace as teachers when teamwork, interpersonal skills and the ability of self-reflection were emphasised. These authentic assessment experiences with emphasis on social cognition theory, did not only foster transferable lifelong learning skills that learners could apply to other courses, but also could confidently transfer to the school environment when they became the practicing educators. Insights gained in these studies on fostering life long learning capabilities with peer assessment for CSCL are shared as follows:

- Assessment should be a continuous process and formative assessment in the online environment should be encouraged as learners can obtain ongoing feedback from both peers and the facilitator for learning;

- Assessment should be as authentic as possible to the task so that learners can use the transferable skills in the ir future careers;

- Changes made to the assessment design result in the acknowledgement of the synergy between assessments and learning design. Assessment tasks should be modified and redesigned to maximise the benefits of student-centred learning with peer assessment;

- As teacher-educators we need to be risk-takers and always consider teaching to be a "work-in-progress". Such a courageous attitude does not only encourage innovation in our own teaching but it also encourages our education students to try out new even unfamiliar ideas. Different forms of peer assessment that fostered increased feedback by both peers and facilitator have been utilised in this project and have proved effective and useful;

- If teacher-educators aim to promote collaboration among learners and to foster them with the fostering of life long learning capabilities via peer assessment, it is essential that we can create a peer support system in which opportunities are provided for learners to ren- 
der quality feedback, conduct group reflection and take active interaction w ithin learning communities;

- Technology needs to be viewed as a tool to support learning and not as a means of transmitting information or perpetuating teacher-centred approaches;

This peer assessment practice reflecting the nature of computer supported collaborative learning can be used in any situation where students are required to work in teams to produce a joint outcome:

- Deriving a set of negotiable assessment criteria helps students to come to grips with what is expected in a task. It also helps them to appreciate the criteria and standards for which they need to strive. Students have a greater sense of ownership of criteria they have developed themselves, and will self-monitor their own work. Furthermore, this exercise helps them to discover which of their own assessment criteria actually "worked" in practice, and allows them to learn more about the choice of suitable criteria relating to the assessment of design;

- Extensive feedback is provided both within groups and between groups, with the Blackboard Learning System MLC environment facilitating the sharing of work as it develops and opportunities to revise their work after receiving ongoing feedback should be provided to promote self-enhancement;

- The continuous flow of feedback allows it to be taken on board constantly through the assessment process, rather than in one instalment at the end of the process in which students are continuously a lerted to the qualities of their peers' work, allow ing them to progressively emulate others' excellence, and avoid any pitfalls they observe in their peers' work; and

- The process of providing feedback to other groups requires careful consideration of appropriate criteria and helps students develop their ability to gauge the quality of the ir own work.

Each practice summarized above is adaptable and lends itself to modification to suit particular contexts to support student-centred learning and contribute to desirable learning outcomes, preparing them to be lifelong learners. The practices are not finite. They are generated out of a particular context in which this research project is undertaken. These practices cannot be directly applied to a new situation without modifications. However, these practices will stimulate thought, be adapted in small or major ways, and lead to better, more effective practices for academics and better learning experiences and opportunities for students.

\section{References}

Aspin, D. N., \& Chapman, J. D. (2007). Lifelong learning concepts and conceptions. In D. N. Aspin (Ed.), Philosophical perspectives on lifelong learning. Springer.

Arias, E., Eden, H., Fisher, G., Gorman, A., \& Scharff, E. (2000). Transcending the individual human mind-Creating shared understanding through collaborative design. Retrieved July 2003, from http://www.cs.colorado.edu/ gerhard/papers/tochi2000.pdf

Boud, D. (1995). Enhancing learning through selfassessment. London: Kogan Page.

Boud, D. (2001). Introduction: Making the move to peer learning. In D. Boud, R. Cohen, \& J. Sampson (Eds.), Peer learning in higher education (pp. 1-19). London: Kogan Page.

Boud, D., Cohen, R., \& Sampson, J. (1999) Peer learning and assessment. Assessment and Evaluation in Higher Education, 24(4), 413-426. 
Brindley, C., \& Scoffield, S. (1998). Peer as ses sment in undergraduate programmes, Teaching in Higher Education, 3(1), 79-89.

Brown, S., \& Knight, P. (1994). Assessing learning in higher education. London: Kogan Page.

Buchanan, T. (2000). The efficacy of a World-Wide-Web mediated formative assessment. Journal of Computer Assisted Learning, 16, 193-200.

Chang, C. C. (2001). Construction and evaluation of a web-based learning portfolio system: An electronic ass essment tool. Innovations in Education and Teaching International, 38(2), 144-155.

Daniel, E. (2001). Participant interaction models and roles in a computer supported collaborative learning (CSCL) environ ment: A Malaysian case study. Proceedings of ED-MEDIA 2001 World Conference on Educational Multimedia, Hypermedia \& Telecommunications, (p.112-133). Un iversity of Finland, Tampere.

Davenport, E. (2001). Knowledge management is sues for online organizations: 'Communities of pract ice' as an exploratory framework. Journal of Documentation, 57(1), 61-75.

Davies, P. (2000). Co mputerized peer ass essment. Innovations in Education and Training International, 37(4), 346-55.

Dewiyanti, S., Brand-Gruwel, S., Jochems, W., \& Broers, N. J. (2007). Students' experiences with collaborative learning in asynchronous computer-supported collaborative learning environ ments. Computers in Human Behaviour, 23(1), 496-514.

Ewing, J., \& Miller, D. (2002). A framework for evaluating computer supported collaborative learn ing. Educational Technology\& Society, 5(1), 112-118.

Falchikov, N. (1995). Peer feedback marking: Developing peer assessment. Innovations in Education \& Training International, 32(2), 175-187.

Fischer, G. (1999). Social creativity: Bringing different points of view together. KBS Special Issues "C\&C '99”. Retrieved 30 July 2003 from $\underline{\text { http://13d.cs.colorado.edu/ gerhard/papers/cc99.pdf }}$

Fry, S. A. (1990). Implementation and evaluation of peer marking in higher education. Assessment and Evaluation in Higher Education, 15, 187-189.

Gatfield, T. (1999). Examining student satisfaction with group projects and peer assessment. Assessment and Evaluation in Higher Education, 24(4), 365-377.

Ge, X., Yamashiro, K. A., \& Lee, J. (2000). Pre-class planning to scaffold students for online collaborative learning activities. Educational Technology \& Society, 3(3), 159-168.

Gillies, R. M. (2004). The effects of co-operative learning on junior high schools students during small group learning. Journal of Learning and Instruction, 14(2), 197-213.

Hung, D., \& Nichani, M. R. (2002). Bringing communities of practice into schools: Implications for instructional technologies from Vygotskian perspectives. International Journal of Instructional Media, 29(2), 171-183.

Jonassen, D. H., Howland, J., Moore, J., \& Marra, R. M. (2003). Learning to solve problems with technology: A constructivist approach. New Jersey: Merrill Prentice Hall.

Kember, D., Jones, A., Loke, A., McKay, J., Singlair, K., Tse, H., Webb, C., Wong, F., Wong, M., \& Yeung, E. (1999). Determining the level of reflective thinking from students' written journals using a coding scheme based on the work of Mezirow. International Journal of Lifelong Education, 18(1), 1830 .

Keppell, M., Au, E., Ma, A., \& Chan, C. (2005). Curricu lu m develop ment in technology-enhanced environments. In C. Howard, P. Rogers, J. V. Boettcher, G. A. Berg, L. Justice, \& K. Schenk (Eds.), Encyclopedia of distance learning: Volume I-IV (pp. 492-504). Hershey, PA: IDEA Group Reference.

Keppell, M., Au, E., Ma, A., \& Chan, C. (2006). Peer learning and learning-oriented assessment in technology-enhanced environments. Assessment and Evaluation in Higher Education, 31(4), 453-464. 
Kreijins, K., \& Kirschner, P. A. (2002). Group awareness widgets for enhancing social interaction in computer-supported collaborative learning environ ments: Design and implementation. Proceedings of $32 \mathrm{nd}$ ASEE/IEEE Frontiers in Education Conference, (p. 134-142). Boston, MA.

Kvan, T., Yip, W. H., \& Vera, A. (1999). Supporting design studio learning: An investigation into design communication in computer-supported collaboration. In C. Hoadley \& J. Roschelle (Eds.), Proceedings of the Computer Support For Collaborative Learning (CSCL) 1999 Conference, (p. 78-88), Stanford University, California. Mahwah, NJ: Lawrence Erlbau m Associates.

Kwok, R., \& Ma, J. (1999). Use of a group support system for collaborative assessment, Computers \& Education, 32, 109-125.

Mcdonald, J. (2003). Assessing online collaborative learning: Process and product. Computers \& Education, 40(4), 377-391.

Macdonald, J., Weller, M., \& Mason, R. (2002). Meeting the assessment demands of networked courses. International Journal on E-learning, 1(1), 9-18.

Misanchuk, M., Anderson, T., Craner, J. Eddy, P., \& Smith, C. (2000). Strategies for creating and supporting a community of learners. Annual Proceedings of Selected Research and Development Papers Presented at the National Convention of the Association for Educational Communications and Technology, Vol 1-2. Denver, CO. (ERIC Docu ment Reproduction No. ED 455785).

Nach mias, R., Mioduser, D., Oren, A., \& Ram, J. (2000). Web-supported emergent-collaboration in higher education courses. Educational Technology \& Society, 3(3), 94-104.

Oldfield, K. A., \& MacAlpine, J. M. K. (1995). Peer and self-assessment at tertiary level-An experiential report. Assessment \& Evaluation in Higher Education, 20(1), 125-132.

Ors mond, P., Merry, S., \& Reiling, K. (1997). A study in self-assessment: tutor and students' perceptions of performance criteria. Assessment and Evaluation in Higher Education, 22(4), 357-369.

Ors mond, P., Merry, S., \& Reiling, K. (2000). The use of student derived marking criteria in peer and selfassessment. Assessment \& Evaluation in Higher Education, 25(1), 23-38.

Ramsden, P. (2003) Learning to teach in higher education. London: Routledge Falmer.

Resta, P., Awalt, C., \& Menchaca, M. (2002). Self and peer assessment in an online collaborative learn ing environment. Proceedings of the World Conference on E-Learning in Corp., Govt., Health \& Higher Ed., 1, 682-689.

Resta, P., \& Laferriere, T. (2007). Technology in support of collaborative learning. Educational Psychology Review, 19, 65-83.

Rubenson, K. (2001). Lifelong learning for all: Challenges and limitations of public policy. Conference Report of Adult Lifelong Learning in a Europe of Knowledge 2001, (p. 28-38). Eskilstuna, Sweden

Shellens, T., \& Valcke, M. (2005). Collaborative learning in asynchronous discussion groups: What about the impact on cognitive process? Computers in Human Behaviour, 21(6), 957-975.

Sivan, A. (2000). The implementation of peer assessment: an action research approach. Assessment in Education, 7(2), 193-209.

Swan, K., Shen, J., \& Hiltz, S. (2006). Assessment and collaboration in online learning. Journal of Asynchronous Learning Networks, 10(1), 44-61.

Tal, R. T. (2001). Co mmunity-based science-technology-society education - A case study. Proceedings of the IOSTE Symposium in Southern Europe 2001, Volume I and Volume II, (p. 132-145). Paralimn i, Cyprus.

Thelwall, M. (2000). Computer-based assessment: a versatile educational tool. Computers \& Education, $34,37-49$. 
Tuijn man, A. C. (2002). Research agenda for lifelong learning: A report by the task force of the International Academy of Education. In A. C. Tuijnman \& T. Schuller (Eds.), Lifelong learning policy and research, (p. 1-22). London: Portland Press.

Wang, C. X., \& Kinuthia, W. (2004) Defining technology enhanced learning environments for pre-service teachers. Proceeding s of Society for Information Technology and Teacher Education International Conference, 2004(1), 2724-2727.

Wegerif, R. (2004). The role of educational software as a support for teaching and learning conversations. Computers and Education, 43(1-2), 179-191.

\section{Biography}

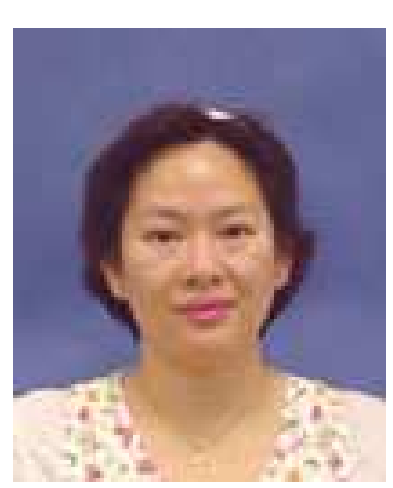

Ada Ma is the lecturer of Technology and Living Division of the Department of Mathematics, Science, Social Sc iences and Technology, at the Hong Kong Institute of Education. She is currently teaching Technology and Living with a focus on textiles for both full-time and parttime Bachelor Degree programmes. She is interested in various research areas such as computer-supported collaborative learning, textiles education, curriculum innovations, assessment, life long learning and gender issues. She has participated actively in various academic activities ranging from publication of conference proceedings, journals and book chapters to being a research investigator of internal and external funded projects. 